INTUISI 12 (1) (2020)
INTUISI
JURNAL PSIKOLOGI ILMIAH
$\begin{gathered}\text { http://journal.unnes.ac.id/nju/index.php/INTUISI } \\ \text { Terindeks DOAJ: 2541-2965 }\end{gathered}$

\title{
EFEKTIVITAS BIBLIOTERAPI KELOMPOK UNTUK MENURUNKAN AGRESIVITAS SISWA SEKOLAH DASAR
}

\author{
Fikri Tahta Nurul Fiqih, Annita Wahyuningtyas, Abid Abdi Aziz, Erni Agustina Setiowati ${ }^{\bowtie}$
}

Fakultas Psikologi, Universitas Islam Sultan Agung, Indonesia

\begin{tabular}{l}
\hline Info Artikel \\
\hline Sejarah Artikel: \\
Disubmit 17 Februari 2019 \\
Direvisi 1 April 2020 \\
Diterima 24 Maret 2020 \\
\hline
\end{tabular}

Keywords:

Agressiveness, Group

Bibliotherapy,

Elementary Student

\begin{abstract}
Abstrak
Penelitian ini bertujuan untuk mengetahui efektivitas biblioterapi kelompok dalam menurunkan agresivitas pada siswa sekolah dasar. Penelitian ini menggunakan metode eksperimen dengan desain Pretest-Postest Control Group Desain. Sampel dipilih berdasarkan hasil seleksi menggunakan skala agresivitas. Penempatan kelompok eksperimen menggunakan randomisasi. Sebanyak 18 siswa sebagai kelompok eksperimen dan 18 siswa sebagai kelompok kontrol. Alat ukur yang digunakan untuk pretest dan post test adalah skala agresivitas yang terdiri dari 55 pernyataan. Biblioterapi dilaksanakan sebanyak 7 sesi dengan menggunakan naskah-naskah cerita yang telah mendapat penilaian kelayakan dari Psikolog. Hasil analisis data menggunakan uji $\mathrm{F}$ menghasilkan perbedaan agresivitas yang signifikan antara gainscore kelompok eksperimen dan kontrol. Selain itu terdapat perbedaan agresivitas yang signifikan pada kelompok eksperimen sebelum dan sesudah intervensi, sedangkan pada kelompok control tidak ada perbedaan agresivitas yang signifikan antara pretest dan post test. Dapat disimpulkan bahwa biblioterapi kelompok dapat menurunkan agresivitas siswa.
\end{abstract}

\begin{abstract}
This study aims to determine the effectiveness of bibliotherapy in reducing aggressiveness in elementary students. This study used an experimental method with the pretest-posttest control group design. The sample is chosen based on the results of the selection using an aggressiveness scale. Placement of the experimental group using randomization. A total of 18 students as the experimental group and 18 students as a control group. The measuring instrument used for the pretest and post-test is an aggressiveness scale consisting of 55 statements. Bibliotherapy was carried out as many as seven sessions using story scripts that had received a feasibility assessment from a Psychologist. The results of data analysis using the F test produced a significant difference in aggressiveness between the gain score of the experimental and control groups. The results showed that there were substantial differences in aggressiveness in the experimental group before and after the intervention. Whereas, in the control group, there was no significant difference in aggressiveness between the pretest and post-test. It can be concluded that bibliotherapy effectively reduces student aggressiveness.
\end{abstract}

(C) 2020 Universitas Negeri Semarang

Alamat korespondensi: p-ISSN 2086-0803

Fakultas Psikologi, Universitas Islam Sultan Agung, e-ISSN 2541-2965

Jalan Raya Kaligawe Km. 4 Semarang, 50112 , Indonesia

erniagustina@unissula.ac.id 


\section{PENDAHULUAN}

Setiap anak memiliki tumbuh dan kembang yang berbeda sesuai karakternya terutama dalam masalah perilaku agresif. Siswa SD yang berada pada tahapan kanakkanak akhir sering mengalami masalah agresivitas. Masalah ini biasanya terjadi karena faktor lingkungan, teman sebaya, keluarga dan media massa. Seperti kasus seorang anak Sekolah Dasar di Sukabumi yang meninggal karena perkelahian yang terjadi dengan temannya (Sindonews.com, 2017). Pada tahun 2016, terjadi kasus tawuran dengan bersenjata tajam antarsiswa sekolah dasar di Semarang yang melibatkan tiga sekolah, yaitu SD Al Khotimah, SD Pangudi Luhur Gunung Brintik, dan SD Negeri Pekunden (Liputan6.com, 2016). Berdasarkan berita tersebut dapat diketahui bahwa perilaku agresi dapat menimbulkan akibat yang sangat serius seperti kematian.

Berdasarkan penelitian yang dilakukan Setiowati, Titin, \& Rohmatun (2017) anak dan remaja di area beresiko di Kota Semarang sebanyak $10 \%$ memiliki kecenderungan agresivitas pada kategori tinggi. Hal ini perlu mendapatkan perhatian serius, jika tidak segera ditangani maka akan berdampak pada kehidupan individu itu sendiri maupun pada orang lain atau masyarakat. Perilaku agresi dapat menimbulkan luka fisik hingga gangguan mental bagi para korban. Agresi terjadi tidak hanya sebabkan oleh dorongan dalam diri pelaku tetapi juga berkaitan dengan latar belakang keluarga dimana anak itu tumbuh dan berkembang seperti latar belakang berpendidikan dan pekerjaan orang tua, keharmonisan keluarga, lingkungan sekitar, budaya, dan media massa.

Agresi merupakan perilaku yang dimaksudkan untuk menyakiti orang lain, baik secara fisik maupun psikis (Baron \& Byrne, 2004). Agresi dibedakan berdasarkan bagaimana perilaku itu dilakukan (Rahman, 2013): 1) agresi dilakukan secara langsung (ditunjukkan secara langsung ke korban) atau tidak langsung (dilakukan orang lain atau benda yang berhubungan), 2) agresi dilakukan secara aktif (menyakiti orang lain menunjukan tindakan atau kata-kata) atau pasif (menyakiti orang lain dengan tidak melakukan), 3) agresi dilakukan secara verbal (menyakiti orang lain dengan kata-kata) dan non verbal (menyakiti dengan tindakan) .

Menurut Elisabeth (dalam Tentama, 2013) anak-anak yang menunjukkan perilaku agresif biasanya mengalami lack of social skills. Hal tersebut disebabkan anak kurang mampu menjalin komunikasi yang baik, mengekspresikan perasaan negatif tanpa menyakiti orang lain, mengatasi konflik tanpa melalui pertengkaran, yang pada akhirnya berdampak pada hubungan kelompok atau pertemanan yang terbentuk, sehingga akan menghambat proses perkembangan sosial anak di lingkungannya. Selain itu, menurut Safaria (dalam Tentama, 2013) anak yang memiliki perilaku agresif akan mengalami kesulitan dalam hal penyesuaian diri. Menurut Nitkowski, et.al (dalam Syahadat. 2013) berdasarkan DSM IV, bentuk-bentuk perilaku agresif yang terparah pada masa anak-anak dan remaja dikategorikan sebagai gangguan oposisi menentang atau gangguan perilaku. Gangguan oposisi menentang mencakup pola perilaku yang ditandai dengan berbagai bentuk pertentangan, kemarahan dan balas dendam, sedangkan gangguan perilaku digambarkan sebagai perilaku bermasalah dan merupakan manifestasi dari kekerasan atau agresif. Tingkah laku agresif menyebabkan terjadinya pelanggaran hak asasi orang lain dengan cara tindakan kekerasan, pemukulan, pengeroyokan, pemerkosaan dan tidak merasa bersalah apabila orang lain menderita.

Menurut Wenar \& Kerig (2000) salah satu faktor yang mempengaruhi perilaku agresi adalah kontrol diri yang rendah. Lebih lanjut Cavell (2000) berpendapat bahwa faktor yang berperan terhadap agresivitas adalah faktor biologis, keluarga, kelompok 
atau peer, sosial-kognitif, akademik, gurusekolah, serta komunitas. Faktor biologi yang mempengaruhi agresi masa perinatal dan mekanisme biologi. Sedangkan keluargan berkaitan dengan polah asuh dan family disruptions. Faktor teman terjadi karena adanya tekanan atau penolakan dari kelompok. Faktor sosial kognitif kuranganya kemampuan memahami sosial informasi dengan tepat.

Menurut Sears, Jonathan, \& Anne (Setiowati, Suprihatin, \& Rohmatun, 2017) faktor yang mempengaruhi agresi, diantaranya adalah 1) proses belajar merupakan mekanisme pertama dalam menentukan perilaku agresi pada manusia. 2) penguatan, memainkan peranan penting dalam suatu tingkah laku, bila tingkah laku di beri ganjaran akan mengakibatkan pengulangan atau penghampusan tingkah laku 3) imitasi, semua orang termasuk anak-anak memiliki kencerungan yang kuat dalam meniru perilaku orang lain.

Perilaku agresi dapat dikurangi intensitasnya dengan terapi. Salah satu cara yang dapat diterapkan adalah melalui metode biblioterapi (Shechtman, 2009). Lebih lanjut Shechtman (2009) menyatakan bahwa kekayaan literatur merupakan sumber yang penting untuk membantu anak-anak memahami interaksi manusia, meningkatkan kepekaan dan empati. McCarty dan Chalmers (1997) menjelaskan bahwa biblioterapi sangat bermanfaat bagi siswa yang memiliki kebutuhan khusus atau yang mengalami kesulitan yang serupa dengan yang ada dalam literatur yang didiskusikan dan memberikan kesempatan pada siswa untuk berbicara mengenai masalah yang dihadapi tokoh dalam buku dan kemudian menerapkan konsep yang sama dalam kehidupannya. Menurut Aiex (dalam Forgan, 2002) mengungkapkan terdapat alasan-alasan potensial pengunaan literatur dalam biblioterapi, beberapa diantaranya membantu seseorang mendiskusikan masalah secara bebas, ada banyak solusi untuk sebuah masalah, meringankan tekanan emosi atau mental, mengembangkan konsep diri Terkait dengan agresivitas Newman (2015) dalam studinya mengenai penanganan perilaku agresif siswa sekolah dasar dengan menggunakan biblioterapi diketahui bahwa berdasarkan penilaian guru ada penurunan agresivitas dan atau masalah-masalah sosial. Shechtman (2009) menegaskan bahwa literatur yang digunakan untuk intervensi masalah agresi harus mengarah pada empat tema yakni meningkatkan penanganan emosi, meningkatkan empati, menurunkan legitimasi atas kekuasaan, dan meningkatkan kontrol diri. Lebih lanjut, Biblioterapi tumbuh dari gagasan bahwa membaca dapat berpengaruh terhadap sikap dan perilaku seseorang (Jack \& Ronan, 2008). Sehingga dapat dikatakan apa yang dibaca oleh seseorang akan berpengaruh pada cara pandang, sikap, dan reaksi terhadap sesuatu hal. Biblioterapi merupakan terapi memberikan buku atau cerita bertema tertentu terkait dengan permasalahan pribadi dan sosial untuk membantu individu atau kelompok agar memperoleh insight mengenai masalah pribadinya dan belajar cara-cara yang lebih sehat dalam menghadapi kesulitan (Heath, et.al., 2005; Cook, et.al., 2006).

Biblioterapi dibedakan menjadi dua yaitu biblioterapi kognitif dan biblioterapi afektif (Shechtman, 2009). 1) Biblioterapi kognitif ditujukan untuk membimbing seseorang untuk meningkatkan kemampuan mereka secara mental dan menyelesaikan masalahnya. Karakteristik utama biblioterapi kognitif yaitu merupakan intervensi mandiri (self-help intervention) dapat berupa intervensi tanpa kontak, intervensi dengan kontak minimal seperti kontak melalui telepon, pertemuan di ruang praktek/klinik. Biblioterapi bentuk ini biasa diberikan pada individu dewasa dan sebagian besar diterapkan untuk kasus depresi. 2) Biblioterapi afektif berakar pada teori psikodinamik yang berpandangan bahwa 
penggunaan bacaan untuk membuka pikiranpikiran, perasaan-perasaan dan pengalaman seseorang. Cerita akan membantu dengan memberi kesempatan individu untuk mendapatkan insight. Asumsi lain dari biblioterapi afektif adalah proses identifikasi, eksplorasi, dan refleksi emosi merupakan komponen penting dari proses terapeutik. Melalui identifikasi karakter dalam buku seseorang dapat merasakan berbagai macam emosi yang dapat dikaitkan dengan emosinya sendiri. Peran terapis adalah mendorong proses identifikasi, meredakan emosi dan membantu pengekspresiannya, serta membantu klien (pembaca) berdiskusi dan memahami emosi-emosinya dalam cara yang tidak menilai. Sebagian besar biblioterapi yang diberikan pada anak-anak dan remaja adalah biblioterapi afektif. Terapi ini bila digunakan secara tepat dapat digunakan untuk perkembangan siswa dan penyembuhan emosional (Heath,et.al, 2005; Cook,et.al, 2006), serta pembelajaran sosioemosional anak-anak yang mengalami permasalahan emosi dan perilaku (Mihalas,et.al, 2009; Regan \& Page, 2008) mengembangkan keterampilan sosial dan emosi bagi anak (Setiowati, 2011), masalah kecemasan sosial pada remaja cerdas istimewa (Setiowati \& Wimbarti, 2014), masalah bullying (Gregory \& Vessey, 2004), cemas pada pelajaran matematika (Wilson, 2009), phobia sosial (Chung \& Kwon, 2008), meningkatkan kesadaran emosional pada siswa yang mengalami hambatan emosi dan sosial (Harper, 2010).

Menurut Burns (2004) cerita yang disajikan untuk tujuan terapi harus etis, penuh moral, dan bertanggung jawab. Agar tercapai fungsi terapeutik cerita harus bersifat menolong, konstruktif dan praktis, sehingga mengandung cara yang jitu untuk memecahkan suatu masalah, melejitkan pengalaman hidup, atau meningkatkan kualitas hidup. sedangkan Shechtman (2009) menyatakan bahwa buku yang dipilih untuk biblioterapi afektif harus terdapat masalah yang dialami anak, menyajikan kesulitan yang dialami dan dinamika perilakunya.

Menurut Pardeck (Cook, EarlessVollrath, \& Ganz, 2006) menyatakan empat tahap dasar menerapkan biblioterapi, yaitu mengidentifikasi masalah, memilih buku atau karya sastra yang tepat, menyajikan buku, dan melakukan tindak lanjut membaca buku dengan diskusi. Sedangkan tahapan yang dilalui sebagaimana digagas (Regan \& Page, 2008)diantaranya identifikasi, katarsis, insight, dan universalisme. Universalisme merupakan tahap akhir yang mana seseorang akan paham dan sadar bahwa bukan hanya dirinya yang mengalami masalah tersebut tetapi ada orang lain yaitu minimal karakter dalam cerita memiliki masalah yang sama. Setiap tahapan melibatkan proses diskusi yang dipandu konselor.

Berdasarkan tahapan perkembangan psikososial dari Erikson dan riset Lindeman dan King (dalam Heath, et.al, 2005) terdapat tiga permasalahan yang dialami oleh siswa yaitu problem-problem emosional yang berakar pada penyakit mental, isu-isu penyesuaian situasional, dan gangguan yang terkait adanya transisi dalam perkembangan. Adanya potensi permasalahan ini menjadikan buku bacaan memiliki peranan strategis dalam membantu mereka tumbuh menjadi individu yang sehat secara psikologis.

Berdasarkan permasalahan tersebut peneliti tertarik untuk melakukan penelitian eksperimen dengan menggunakan biblioterapi sebagai salah satu intervensi dalam psikologi untuk menangani masalah agresivitas. Peneliti mengajukan hipotesis apakah biblioterapi efektif untuk menurunkan masalah agresivitas pada siswa SD.

\section{METODE}

Skrining sampel dilakukan dengan memilih SD yang ditengarai terjadi kasus agresivitas, sehingga ditentukan di SD Islam Sultan Agung 4, SD Gebangsari 03, dan SDN 
Pekunden. Penentuan siswa SD yang diteliti secara purposif yang didasarkan pada jumlah siswa yang melakukan perilaku agresif tinggi. Diperoleh SD N Pakunden yang berjumlah 36 sampel yang kemudian penugasan kedalam kelompok eksperimen dan kelompok kontrol menggunakan random assignment. Screening menggunakan skala agresivitas yang dikembangkan oleh Setiowati, Titin, \& Rohmatun (2017). Skala ini terdiri dari 55 pernyataan, indeks daya beda aitem $=0,404$ 0,631 , koefisien reliabilitas 0,955 . Skala ini terdiri dari 55 pertanyaan. Salah satu aitem dari skala yang dipakai yaitu "Mencaci (mengata-ngatai) teman".

Metode yang dipilih adalah eksperimen dengan rancangan pretest- postest with control group design. Kelompok eksperimen dan kontrol dikenakan pretest menggunakan skala agresivitas. Kelompok eksperimen diberikan intervensi biblioterapi kelompok dan setelah selesai, diberikan post test dan kelompok kontrol diberi post test tanpa adanya perlakuan. Kelompok kontrol diperlakukan sebagai kelompok waiting list, yang diberikan perlakuan serupa dengan kelompok eksperimen namun dilakukan sesudah post test. Hal ini dilakukan agar terpenuhi asas keadilan.

Biblioterapi yang dilakukan terdiri dari 6 sesi dan dilakukan sebanyak 6 kali pertemuan memiliki asumsi dasar psikoanalisa. Pada tiap sesi disediakan naskah-naskah cerita yang terdiri dari 3 sampai 5 halaman yang telah dinilai oleh Psikolog Pendidikan berisi tentang nilai-nilai moral diantaranya empati, kebersamaan, toleransi, tolong menolong, kesetaraan atau persamaan hak dan kewajiban, rasa memiliki terhadap teman, kasih saying, menghargai dan menghormati, serta rasa mampu mengatasi masalah. Selain itu, dalam penelitian ini menggunakan kartu evaluasi untuk menunjang seberapa efektif terapi biblioterapi yang telah dilakukan.
Tahapan yang dilalui dalam tiap sesi adalah tahap pertama, pelibatan terhadap isi cerita, terapis mengenalkan judul dan tokoh dalam cerita kemudian mengajak siswa bersama-sama membaca dalam hati. Tahap kedua identifikasi, pada tahap ini siswa dibimbing untuk mengidentifikasi tokohtokoh dalam cerita, mana yang disukai dan tidak disukai dan mana yang lebih mendekati gambaran dirinya. Tahap ketiga, katarsis yaitu ketika siswa mulai terlibat secara emosional dengan isi cerita dan mampu mengeluarkan perasaan-perasaannya yang terpendam dalam kondisi yang aman sehingga respon seperti melampiaskan kemarahan, kesedihan, kegalauan dengan berteriak, meninju atau memukul objek yang aman, perasaan malu, manangis dibiarkan muncul. Tahap keempat, insight yang merupakan hasil dari pengalaman katarsis, siswa lebih menyadari masalahmasalahnya dan solusi-solusi yang mungkin bagi mereka berdasarkan bagaimana solusi dalam naskah cerita maupun solusi yang ia peroleh secara insight. Tahap kelima, universalitas yakni siswa memiliki pandangan bahwa ternyata tidak hanya dirinya yang memiliki masalah agresivitas, namun ada banyak orang lain yang mengalami masalah yang membuat mereka dapat bertindak agresif namun mereka mampu dan memiliki cara-cara mengatasi masalahnya dan tidak berkelanjutan dalam melakukan perilaku agresif.

Intervensi biblioterapi kelompok yang bertujuan untuk menurunkan agresivitas pada siswa sekolah dasar diberikan dalam 6 sesi yang dilakukan sebanyak 6 kali pertemuan. Pada setiap akhir sesi tiap sampel yang berada di kelompok eksperimen diberi kartu yang berisi pertanyaan-pertanyaan mengenai kejadian yang menimbulkan amarah.

Sesi pertama menggunakan cerita berjudul "Memaku Amarah". Peserta mengikuti kegiatan mulai dari proses pelibatan dan identifikasi tokoh. Peserta mengungkapkan identifikasi diri mereka dengan tokoh Budi dan ayah Budi dalam 
cerita itu. Peserta dalam sesi ini diajak untuk memahami perilaku amarah serta dampaknya bila perilaku marahnya dalam bentuk destruktif.

Sesi kedua menggunakan cerita "Bumi dan Bulan". Peserta mengikuti kegiatan mulai dari proses pelibatan dan indentifikasi tokoh. Peserta mengungkapkan indentifikasi diri mereka dengan tokoh Ardi. Tokoh dalam cerita ini digambarkan bahwa tokoh Ardi suka mengejek tokoh Komariah. Sesi ini mengajarkan peserta untuk merasakan rasanya diejek dan dampak dari suka mengejek seseorang, karena yang diejek dapat tersakiti perasaannya.

Sesi ketiga menggunakan cerita "Kisah Raja dari India". Peserta mengikuti kegiatan mulai dari proses pelibatan dan indentifikasi tokoh. Mereka mengungkapkan indentifikasi diri mereka dengan tokoh Raja dari india. Dalam cerita ini tokoh digambarkan bahwa Raja dari india sangat jahat dan pelit. Peserta diajarkan bahwa semua yang kita perbuat akan mendapatkan balasannya.

Sesi keempat menggunakan cerita "Mengungkapkan Emosi dengan Baik". Kegiatan dimulai dari proses indentifikasi tokoh. Peserta menggungkapkan indentifikasi diri mereka dengan tokoh Rere. Tokoh Rere digambarkan sebagai tokoh yang pintar, sabar dan berani bereksperimen. Peserta diajarkan untuk tidak cepat marah, lebih bersabar, mau belajar hal positif dari orang lain dan tidak boleh berteriak-teriak.

Sesi kelima menggunakan cerita berjudul "Kena Akibatnya". Peserta mengikuti kegiatan mulai proses pelibatan dan indentifikasi tokoh. Mereka mengidentifikasikan diri dengan tokoh dalam cerita yaitu tokoh Arga, Inka dan Gendis. Arga memiliki watak yang nakal dan suka mengejek, Inka dan gendis pemaaf dan pemarah. Peserta diajarkan untuk tidak boleh mengejek, jangan menyimpan rasa dendam dan berani mengungkapkan permintaan maaf.

Sesi keenam merupakan sesi terakhir. Sesi ini menggunakan cerita berjudul "Pikir Dulu Akibatnya". Peserta mengikuti kegiatan mulai proses pelibatan dan indentifikasi tokoh. Peserta mengungkap indentifikasi tokoh Windi. Tokoh Windi memiliki watak yang nakal dan suka mengejek. Peserta diajarkan bahwa setiap perbuatan yang kita lakukan pasti ada akibatnya baik positif maupun negatif. Selian itu peserta juga diajarkan untuk berani meminta maaf apabila berbuat kesalahan.

Setiap sesi didampingi oleh terapis. Peran terapis adalah mendorong proses identifikasi, meredakan emosi dan membantu pengekspresiannya, serta membantu siswa berdiskusi dan memahami emosi-emosinya dalam cara yang tidak menilai. Setelah semua sesi selesai, dilakukan post test dan follow up measurement satu bulan sesudah post test untuk mengetahui panjang efek intervensi. Analisis data menggunakan analisis of variance dan uji $t$ correlated samples melalui program komputer SPSS.

\section{HASIL DAN PEMBAHASAN}

Uji prasyarat dilakukan peneliti sebelum melakukan uji hipotesis. Berdasarkan hasil uji normalitas data, diketahui data hasil post test dan data gained score berdistribusi normal, dengan nilai $\mathrm{KS}-\mathrm{Z}$ masing-masing pada $p=.200$. Sehingga analisis dilanjutkan menggunakan analisis statistik parametrik. Analisis statistik dilakukan terhadap 18 pasang data yakni bersumber dari pretest dan post test. Tabel 1 Hasil uji $\mathrm{t}$ correlated samples pada kelompok eksperimen dan control pada saat pengukuran pretest dan post test. 
Tabel 1

Hasil Analisis Statistik pada kelompok eksperimen dan kelompok kontrol

\begin{tabular}{llllccc}
\hline \multicolumn{1}{c}{ Sumber } & & Rerata & N & Simpangan baku & T & P \\
\hline Kelompok & Pretest & 67,44 & 18 & 14,370 & & \\
Eksperimen & Post test & 49,11 & 18 & 25,925 & 3,696 & 0,002 \\
Kelompok & Pretest & 67,44 & 18 & 14,370 & & \\
control & Post test & 64,61 & 18 & 26,602 & 0,401 & 0,693 \\
\hline
\end{tabular}

Hasil analisis data menggunakan ANOVA diketahui terdapat perbedaan yang signifikan antara gainscore atau selisih skor kelompok eksperimen dan kontrol diperoleh nilai $F=3.224, p=0.041$, selain itu terdapat perbedaan yang signifikan pada kelompok eksperimen sebelum dan sesudah intervensi, $t$ $=3.696, p=.002$, sedangkan pada kelompok kontrol tidak ada perbedaan yang signifikan antara pretest dan post test, $t=0.401, p=.693$ karena itu dapat disimpulkan bahwa biblioterapi kelompok dapat menurunkan agresivitas siswa. Kemudian analisis dilanjutkan untuk mengetahui apakah ada perbedaan perilaku agresif kelompok eksperimen pada saat post test dan pengukuran follow-up yang dilakukan setelah satu bulan post test. Berikut hasil analisis statistik terhadap kedua data tersebut.

Tabel 2

Hasil uji statistik post test dan pengukuran follow up pada kompok eksperimen

\begin{tabular}{clccccc}
\hline Sumber & & Rerata & N & Simpangan baku & t & P \\
\hline \multirow{2}{*}{ Pasangan } & Post test & 48,56 & 16 & 26,510 & & \\
& Follow up & 37,00 & 16 & 19,933 & 2,661 & 0,018 \\
\hline
\end{tabular}

Analisis pengukuran post dan follow up pada kelompok eksperimen menggunakan paired-samples $t$-test diperoleh nilai $t=2,661$, $p=.018$. Hal ini berarti terdapat perbedaan perilaku agresivitas saat post test dan follow up measurement secara signifikan, sehingga disimpulkan bahwa intervensi biblioterapi kelompok mampu menurunkan perilaku agresivitas secara menetap hingga satu bulan sesudah intervensi diberikan.

Hasil penelitian menunjukkan bahwa intervensi biblioterapi kelompok dapat menurunkan perilaku agresivitas secara menetap hingga satu bulan sesudah intervensi diberikan. Hasil ini sejalan dengan studi yang dilakukan oleh Puspitasari (2011) terhadap sekelompok siswa kelas IV SD menunjukkan bahwa setelah diberi intervensi afektif biblioterapi terdapat penurunan perilaku agresif yang signifikan. Selain itu kajian yang dilakukan oleh Fadhila (2013) terhadap siswa kelas VIII diperoleh fakta bahwa biblioterapi dapat meningkatkan kemampuan mengelola emosi marah. Rasa marah sebagaimana telah diketahui secara umum meningkatkan kemungkinan munculnya agresi.

Hasil positif ini tidak terlepas dari naskah cerita yang digunakan dalam biblioterapi maupun proses intervensi biblioterapi itu sendiri. Kriteria buku atau naskah cerita yang digunakan dalam biblioterapi telah dinilai dan berisi kisah yang memuat isi yang relevan dengan masalah agresivitas seperti akibat kemarahan, meningkatkan empati, persahabatan, menggunakan kekuatan untuk hal yang positif, dan kontrol diri. Melalui naskah tersebut subjek memperoleh referensi untuk berperilaku secara tepat dalam situasi yang menyenangkan. Hal ini sesuai dengan 
Stoneburg, Hutcheson, \& ALA (dalam Swart, 1984) yang menyatakan bahwa literasi penuh dengan informasi yang dapat digunakan untuk sebuah terapi.

Pada penelitian ini subjek dibawah panduan terapis melalui 4 tahapan, pertama pelibatan yang menjadikan subjek berada dalam situasi mengenal judul cerita dan membaca bersama-sama, selanjutnya subjek mengidentifikasi emosi-emosi karakter yang ada dalam cerita dan mengeksplorasi dinamika dari perilaku tokoh. Hingga kemudian subjek memahami perasaan dan perilakunya sendiri. Ada strategi yang sangat penting yang dilakukan oleh konselor pada tahap ini yakni proses klarifikasi. Shechtman (2009) berpendapat bahwa proses klarifikasi membantu anak-anak mengevaluasi derajat agresivitasnya sendiri, membuat keputusan terkait perubahan perilaku yang diinginkan dan mengetahui bagaimana agar dapat mencapai hasil yang diinginkan.

Selain itu, hasil penelitian ini sejalan dengan kajian yang dilakukan oleh Newman (2015) terhadap siswa yang berusia 9 sampai 11 tahun yang menerapkan delapan sesi intervensi biblioterapi untuk menurunkan agresivitas. Hasil analisis data pra intervensi dan sesudah intervensi pada penelitian ini menunjukkan bahwa ada dua pertiga siswa mengalami penurunan perilaku agresif yang cukup besar (Newman, 2015). Pada studi yang dilakukan peneliti hal serupa juga dijumpai. Perubahan-perubahan perilaku tampak dari hasil observasi pertemuan pertama sampai pada pertemuan terakhir. Tiap sesi subjek selain dihadapkan pada situasi yang menjadikannya memahami tindakan dan menilai tindakan karakter dalam cerita dan dilanjutkan dengan mengingat dan mengevaluasi perilakunya. Hal ini mengarahkan subjek memiliki kesadaran diri yang semakin lebih baik dari sebelumnya.

Adanya kisah atau cerita yang disampaikan dalam bentuk bacaan menjadi inspirasi dalam memandang persoalan yang dihadapi. Cronje (1993) mengungkapkan membaca memiliki banyak sekali manfaat dalam proses terapi diantaranya individu mendapatkan efek positif dalam kepribadian, membantu menyelesaikan permasalahan pribadi yang dimiliki, meningkatkan potensi dalam pertumbuhan dan perkembangan. Selain itu, Cronje menambahkan membaca dapat mengarahkan individu mampu menyesuaikan diri dengan dunia yang terus berubah dan membantu individu untuk mengatasi kesulitan dalam bentuk psikologis, emosional serta sikap positif terhadap dirinya dan lingkungan (Cronje, 2013).

Sikap atau perilaku destruktif yang dapat mengganggu aktivitas diri sendiri maupun orang lain juga perlu penanganan yang serius seperti perilaku agresif. Adanya "support group" dalam intervensi biblioterapi yang disajikan secara berkelompok (group bibliotherapy) mengarahkan subjek dalam suatu pemahaman bahwa bukan hanya dirinya yang memiliki permasalahan yang dialami dan ada banyak orang lain yang mengalami kesulitan-kesulitan yang sama atau yang disebut dengan universalisme yang merupakan fase akhir. Peran terapis pada biblioterapi memegang peranan penting pada fase ini. Shechtman (2009) menyatakan bahwa terapis akan bertanya, mendorong, melakukan parafrase dan menyimpulkan pernyataan-pernyataan, refleksi atas perasaanperasaan, interpretasi, tantangan, bimbingan, dan keterbukaan diri. Umumnya ketika anak melakukan tindakan yang tidak baik mereka akan mengkritik dan menilai buruk, akan tetapi dalam biblioterapi anak-anak mendapat pengalaman interpersonal baru dengan menggunakan pernyataan-pernyataan terapeutik.

Prosedur biblioterapi yang digunakan dalam penelitian ini mengikuti model biblioterapi afektif yang mana peran terapis dalam mengelola kelompok subjek sangat besar sehingga pemilihan terapis yang tepat menjadi isu yang krusial. Oleh karena itu 
ketika akan diterapkan dalam skala yang lebih besar menjadi tidak mudah. Hal ini berbeda dengan biblioterapi kognitif yang dapat disajikan secara mandiri (self help intervention) atau dengan kontak yang minimal dengan terapis. Selain itu, intervensi biblioterapi kelompok dilakukan di sekolah asal subjek dan dilakukan sebanyak 6 kali pertemuan dalam waktu 3 minggu, dalam kurun waktu tersebut memungkinkan adanya kejadian-kejadian yang tidak dapat dikontrol oleh peneliti yang dapat mempengaruhi hasil penelitian, meskipun peneliti berupaya mengidentifikasi kejadian-kejadian yang dialami oleh subjek diluar proses intervensi yang dapat mengganggu proses penelitian.

\section{SIMPULAN}

Berdasarkan penelitian ini dapat disimpulkan bahwa intervensi biblioterapi kelompok terbukti efektif untuk menurunkan perilaku agresivitas pada siswa sekolah dasar dan efektif untuk menurunkan perilaku agresivitas secara menetap hingga satu bulan sesudah intervensi diberikan.

Intervensi biblioterapi kelompok dapat diimplementasikan di sekolah dasar, karena terbukti dapat menurunkan perilaku agresivitas pada siswa sekolah dasar dan dapat menjadi sarana untuk melestarikan budaya membaca yang baik untuk membentuk karakter anak. Sedangkan saran untuk penelitian selanjutnya, agar dapat secara ketat menetapkan kualifikasi terapis untuk mengelola biblioterapi afektif yang dilakukan secara berkelompok selain itu setting dan jeda waktu antar sesi dalam intervensi dapat diatur sedemikian rupa untuk menjaga munculnya kondisi yang dapat merusak proses penelitian.

\section{UCAPAN TERIMAKASIH}

\section{Terima kasih}

kepada

Kemenristekdikti yang telah memberikan pendanaan penelitian ini melalui Hibah Program Kreativitas Mahasiswa (PKM) tahun 2018.

\section{DAFTAR PUSTAKA}

Baron, R., \& Byrne, D. (2004). Psikologi Sosial (Kesepuluh). Jakarta: Erlangga.

Cavell, T. A. (2000). Working with parents of aggressive children. Washington DC: American Psychological Association.

Chung, Y. S., \& Kwon, J. H. (2008). The efficacy of bibliotherapy for social phobia. Brief Treatment and Crisis Intervention, 8(4), 390-401. doi: 10.1093/brief-treatment/mhp001

Cook, K. E., Eearles-Vollrath, T., \& Ganz, J. B. (2006). Bibliotherapy. Intervention in School and Clinic, 42(2), 91-100.

Cronje, K. B. (1993). Bibliotherapy in seventh-day adventist education: Using the information media for character development. Institute for Christian Teaching. Education Department of Seventh-Day Adventists, 49-66. doi: 10.1017/CBO9781107415324.004

Fadhila, S. M. (2013). "Peningkatan kemampuan mengelola emosi marah melalui teknik biblioterapi pada siswa kelas VIII di SMP Negeri 15 Yogyakarta". Skripsi (tidak diterbitkan). Universitas Negeri Yogyakarta, Yogyakarta.

Forgan, J. W. (2002). Using bibliotherapy to teach problem solving. Intervention in School and Clinic, 38(2), 75-83, doi: $10.1177 / 10534512020380020201$

Gregory, K. E., \& Vessey, J. A. (2004). Bibliotherapy: A strategy to help students with bullying. The Journal of School Nursing: The Official Publication of the National Association of School Nurses, 20(3), 127-133. doi: $10.1177 / 10598405040200030201$

Harper, E. (2010). "Bibliotherapy intervention exposure and level of emotional awareness among students with 
emotional and behavioral disorders". Dissertation (unpublished). Cleveland State University. Retrieved from http://gateway.proquest.com/openurl? url_ver=Z39.88-

2004\&rft_val_fmt=info:ofi/fmt:kev:mtx: dissertation\&res_dat=xri:pqdis

s\&rft_dat=xri:pqdiss:3414131\%5Cnhttp: //ovidsp.ovid.com/ovidweb.cgi?T=JS\&P $\mathrm{AGE}=$ reference $\& \mathrm{D}=\mathrm{psyc} 8 \& \mathrm{NEWS}=\mathrm{N} \&$ $\mathrm{AN}=2011-99010-265$

Heath, M. A., Sheen, D., Leavy, D., Young, E., \& Money, K. (2005). Bibliotherapy: A resource to facilitate emotional healing and growth. School Psychology International, 26(5), 563-580. doi: $10.1177 / 0143034305060792$

Ige, E. P. (2016, November 25). Kronologi tawuran bocah sd bersenjata tajam. Liputan6. Retrieved from http://regional.liputan6.com/read/266182 8/kronologi-tawuran-bocah-sdbersenjata-tajam

Jack, S. J., \& Ronan, K. R. (2008). Bibliotherapy: Practice and research. School Psychology International, 29(2), 161-182. doi: $10.1177 / 0143034308090058$

McCarty, H., \& Chalmers, L. (1997). Bibliotherapy intervention and prevention. Teaching Exceptional Children, 29, 12-17. doi: 10.1177/004005999702900603

Mihalas, S., Morse, W. C., Allsopp, D. H., \& Alvarez McHatton, P. (2009). Cultivating caring relationships between teachers and secondary students with emotional and behavioral disorders: Implications for research and practice. Remedial and Special Education, 30(2), 108-125.

doi: $10.1177 / 0741932508315950$

Newman, K. (2015). "Bibliotherapy as an Intervention for Aggressive Elementary Children". Thesis (Unpublished). Department of Counseling Psychology and Special Education, Brigham Young
University.

Nitkowski, D., Petermann, F., Büttner, P., Krause-Leipoldt, C., \& Petermann, U. (2009). Behavior modification of aggressive children in child welfare: Evaluation of a combined intervention program. Behavior Modification, 33(4), 474-492. doi: $10.1177 / 0145445$ 509336700

Puspitasari, D. A. (2011). "Pengaruh biblioterapi afektif untuk menurunkan agresivitas siswa kelas empat". Tesis (tidak diterbitkan). Universitas Gadjah Mada, Yogyakarta.

Rahman, A. A. (2013). Psikologi Sosial: Integrasi Pengetahuan Wahyu dan Pengetahuan Empirik. Jakarta: Rajawali Pers.

Regan, K., \& Page, P. (2008). "Character" Building: Using literatur to connect with youth. Reclaiming Children and Youth, 16(4), 37-43.

Setiowati, E. A. (2011). Mengembangkan ketrampilan sosial dan mengelola emosi bagi anak melalui biblioterapi. In Prosiding Peran pendidik, psikolog, dan orang tua dalam penanaman nilai-nilai bagi anak dan remaja (pp. 19-27). Semarang: Fakultas Psikologi Unissula.

Setiowati, E. A., Suprihatin, T., \& Rohmatun. (2017). Gambaran agresivitas anak dan remaja di area beresiko. In Prosiding temu ilmiah $X$ ikatan psikologi perkembangan indonesia (pp. 170-179). Semarang.

Setiowati, E. A., \& Wimbarti, S. (2014). The effect of group bibliotherapy in reducing social anxiety of gifted and talented adolescents. Anima, Indonesian Psychological Journal, 29(4), 207-220.

Shechtman, Z. (2009). Treating Child and Adolescent Aggression Through Bibliotherapy. New York: Springer.

Swart. (1984). School Media Center: Media 